\title{
Pterin-4a-Carbinolamine Dehydratase from Pseudomonas aeruginosa: Characterization, Catalytic Mechanism and Comparison to the Human Enzyme
}

\author{
Sandra Köster ${ }^{1, b, c}$, Gunter Stier ${ }^{2, b}$, \\ Niels Kubasch ${ }^{1}$, Hans-Christoph Curtius ${ }^{1}$ \\ and Sandro Ghisla ${ }^{1, *}$ \\ ${ }^{1}$ Department of Biology, University of Konstanz, \\ P.O. Box 5560-M644, D-78434 Konstanz, Germany \\ 2 EMBL, Structural Biology Program, Meyerhofstr.1, \\ D-69117 Heidelberg, Germany \\ ${ }^{*}$ Corresponding author
}

The three-dimensional structure of pterin-4a-carbinolamine dehydratase (PCD) from Pseudomonas aeruginosa has been solved. Based on this we have investigated the roles of putative active center residues through functional replacement by site-directed mutagenesis. Three histidines, His73, His74 and His91, appear to be involved in dehydration catalysis. The three-dimensional positions of these residues match those of corresponding histidines at the active center of human PCD. Based on the coincidence of catalytic parameters, and on the similar effects induced by the mutations, it is concluded that the substrate binding mode and the reaction mechanisms of bacterial and human PCD are basically identical.

Key words: DCoH/Dehydratase/Phenylalanine hydroxylase / Tetrahydrobiopterin.

\section{Introduction}

Pterin-4a-carbinolamine dehydratase (PCD) is a small protein which has originally been recognized as taking part in the regeneration cycle of tetrahydrobiopterin $\left[\mathrm{BH}_{4}\right.$, 6(R)-5,6,7,8-tetrahydrobiopterin] during the hydroxylation of aromatic amino acids in mammals, an essential step in the biosynthesis of biogenic amines (Kaufman, 1970). It catalyzes the dehydration of 4a-hydroxy- $\mathrm{BH}_{4}$ (4a-carbinolamine; Scheme 1) to form quinonoid dihydrobiopterin (Kaufman, 1976), a function which additionally prevents the rearrangement of biopterins to their 7-substituted isomers. The latter have been recognized as being detrimen-

\footnotetext{
a Presented in part at the Eleventh International Symposium on Pteridines and Folates, Berchtesgaden, Germany, June 15-20, 1997.

b The two authors have contributed equally to this work.

c Present address: University of Heidelberg, Department of Pharmacology, im Neuenheimer Feld 366, D-69120 Heidelberg, Germany.
}

tal to the hydroxylation system (Curtius et al., 1990). In addition, human PCD acts in the nucleus as dimerization cofactor of hepatocyte nuclear factor- $1 \alpha$ (in this function also abbreviated DCoH) (Mendel et al., 1991). Its threedimensional structure in the absence and presence of a product analog has been solved (Cronk et al., 1996; Endrizzi et al., 1995; Ficner et al., 1995). Most remarkably, it has a saddle-like shape and a striking similarity to the structure of the TATA-box binding protein (Nikolov et al., 1992). Based on the structure of the enzyme complex with the product analog (Cronk et al., 1996) and on the results of site-directed mutagenesis (Köster et al., 1996), the active center of human PCD has been located and a dehydration mechanism has been proposed. A similar mechanism based on studies with recombinant rat liver dehydratase has been subsequently discussed by Ayling et al. (1997).

The occurrence of PCD in lower organisms such as Pseudomonas aeruginosa was first detected by Zhao et al. in 1994. The gene encoding this enzyme lies directly adjacent to the gene for phenylalanine hydroxylase (PAH) from Pseudomonas aeruginosa and both are controlled by the same operon. It has been speculated that PCD from $P$. aeruginosa (PCD/PhhB) regulates the expression of $\mathrm{PAH}$ in the bacterial organism (Zhao et al., 1994); this would be the counterpart of the bifunctional role of PCD in the mammalian organism.

The amino acid sequences of the bacterial and mammalian PCD's are only $\approx 30 \%$ identical (Figure 1 ). On the other hand, the three-dimensional structure of PCD/ PhhB, which has been solved recently (Ficner, R., Sauer,

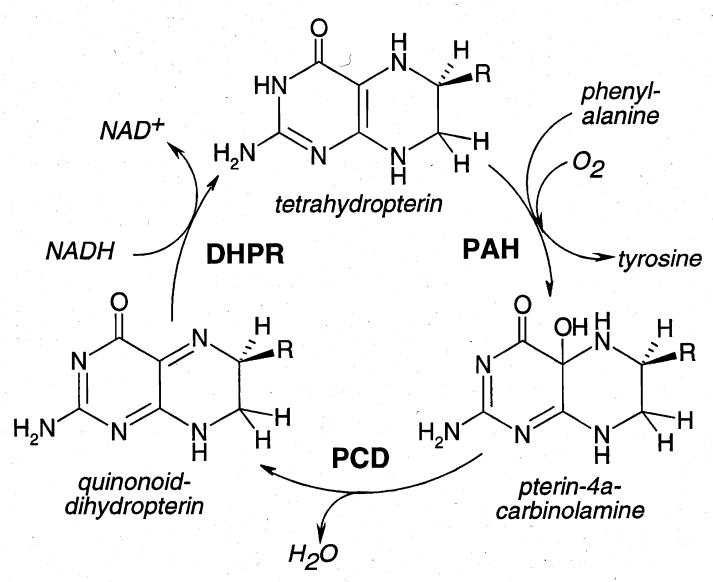

Scheme 1 Enzymes and Pterins Involved in the Hydroxylation of Aromatic Amino Acids.

PAH: phenylalanine hydroxylase, DHPR: dihydropteridine reductase; PCD: pterin-4a-carbinolamine dehydratase. 


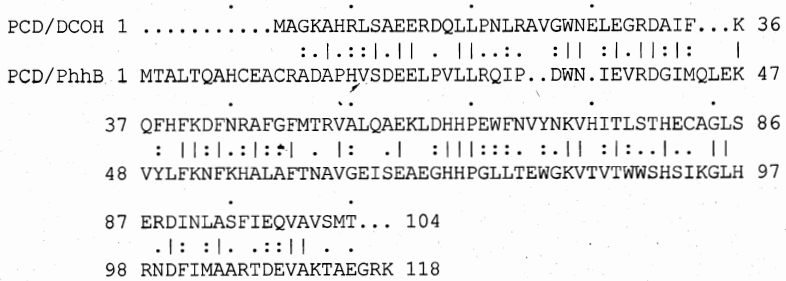

Fig. 1 Alignment of the Amino Acid Sequences of Human and $P$. aerginosa $P C D$.

The sequence of PCD/PhhB contains 12 additional $\mathrm{N}$-terminal and 3 C-terminal residues compared to human wt-PCD $(\mathrm{PCD} / \mathrm{DCOH})$. The sequences were aligned using the HUSAR package (DKFZ, Heidelberg, Germany), which is based on the GCG suite of programs. Similarity between the two sequences is $\approx 60 \%$ and identity is $\approx 30 \%$. The $\mathrm{N}$-terminal methionine of human PCD is cleaved off (Köster et al., 1995).

U.H., Stier, G., Ceska, T.A., and Suck, D, personal communication; Köster et al., 1997) shows very high overall similarity to that of the human enzyme. The bacterial enzyme is a homodimer, while human PCD is a homotetramer, the latter consisting of a dimer of two dimers. Notably, most of the residues which take part in substrate binding or dehydration catalysis are conserved in the two enzymes (Figure 1). These are three histidines $(61,62$ and 79 , human PCD numbering) and two carboxylic acids (Glu57 and Asp88) that form hydrogen bonds with His62 and His61, respectively. The latter could act as general base catalysts in classical pairs with the corresponding carboxylic acids, while His79 could act as general acid catalyst.
This information raised several questions:

a) What is the function of $\mathrm{PCD} / \mathrm{PhhB}$ (lower organisms are not known to have a metabolism of biogenic amines)?

b) Are the catalytic mechanisms the same, or result the differences at the active site in specific functions?

c) Is the peculiar shape of the protein(s) related to their regulatory functions, i.e. does it play a role in the recognition of specific motifs?

d) Does the recognition of pterins affect the regulatory role of the proteins?

To provide partial answers to these queries, we have studied selected biochemical properties of PCD/PhhB in comparison to human PCD. Specifically, we have mutated some of the amino acids mentioned above, and studied the properties of the resulting mutants. An attempt is made to interpret the picture emerging from a comparison of the two proteins.

\section{Results}

\section{Purification of Wild-Type PCD/PhhB and of the Mutant Enzymes}

PCD was expressed in Escherichia coli and purified to apparent homogeneity by affinity chromatography over a $\mathrm{Ni}^{2+}$-nitriloacetic acid-agarose (column) using the following adaptation of previously described methods (Ficner et al., 1995; Köster et al., 1995, 1996). PCD/PhhB contains no 'His-tag'; it nevertheless binds to the affinity column in the absence of imidazole in the buffer. This is

Table 1 Catalytic Properties and Binding Constants of q-6,6- $-\mathrm{Me}_{2}-\mathrm{PH}_{2}$ for $\mathrm{PCD} / \mathrm{PhhB}$, Human PCD and some of their Mutants.

\begin{tabular}{|c|c|c|c|c|c|c|}
\hline \multirow[t]{2}{*}{ Enzyme } & \multicolumn{4}{|c|}{ Activity, direct assay } & \multirow{2}{*}{$\begin{array}{l}\text { Relative activity, } \\
\text { coupled assay } \\
\text { (\%) }\end{array}$} & \multirow{2}{*}{$\begin{array}{l}K_{d} \text { for binding of } \\
\text { product } \\
(\mu \mathrm{M})\end{array}$} \\
\hline & $\begin{array}{l}K_{\mathrm{m}} \\
(\mu \mathrm{M})\end{array}$ & $\begin{array}{l}V_{\max } \\
(\mathrm{nmol} / \mathrm{s})\end{array}$ & $(\%)$ & $\mathrm{pK}$ & & \\
\hline wt-PCD/PhhB & 20 & 3.5 & $100(40)$ & 8.4 & 90 & 2 \\
\hline E69A & 25 & 1.3 & 40 & 8.4 & 30 & 6 \\
\hline D100N & & & $<10$ & 8.3 & 0 & 50 \\
\hline $\mathrm{H} 73 \mathrm{~A}$ & & & $<10$ & & 0 & \\
\hline $\mathrm{H} 74 \mathrm{~A}$ & & & $<10$ & & 0 & \\
\hline $\mathrm{H} 73 \mathrm{~A}, \mathrm{H} 74 \mathrm{~A}$ & & 0 & 0 & & 0 & \\
\hline $\mathrm{H} 91 \mathrm{~A}$ & 60 & 1.4 & 40 & 7.9 & 65 & 10 \\
\hline W81A & & 0 & 0 & & 0 & $>110$ \\
\hline G72D & 20 & 2.7 & 75 & 8.3 & 65 & 1 \\
\hline humant wt-PCD & 25 & 8.6 & 100 & 8.2 & 100 & 0.9 \\
\hline E57A & & 0 & 0 & & 0 & $<165$ \\
\hline $\mathrm{H} 61 \mathrm{~A}$ & 220 & 1 & 12 & 8.0 & $0-2$ & $>55$ \\
\hline $\mathrm{H} 62 \mathrm{~A}$ & 75 & 0.9 & 10 & 7.15 & 16 & $>65$ \\
\hline $\mathrm{H} 61 \mathrm{~A}, \mathrm{H} 62 \mathrm{~A}$ & & 0 & 0 & & $0-2$ & $>140$ \\
\hline $\mathrm{H} 79 \mathrm{~A}$ & 10 & 2.2 & 25 & 7.8 & 40 & 5 \\
\hline Y69F & 8 & 3.5 & 40 & 8.3 & 80 & 4.4 \\
\hline $\mathrm{D} 60 \mathrm{~A}$ & 18 & 2.7 & 30 & 8.1 & 90 & $\cdot 1.5$ \\
\hline
\end{tabular}

$V_{\max }$ is expressed as nmol substrate dehydrated per nmol enzyme subunit per $\mathrm{s}$. The $V_{\max }$ values of wt-PCD's are taken as $100 \%$. The activity for wt-PCD/PhhB is compared to human wt-PCD (in parenthesis). The values for human wt-PCD and its mutants are from Köster et al. (1996). 
attributed to the presence of two histidines in the region of the $\mathrm{N}$-terminus and three histidines that are part of the presumed active center. These five histidines are closely located in the three-dimensional structure. PCD is eluted with buffer containing (the relatively low concentration of) $10 \mathrm{~mm}$ imidazole. At this stage $\mathrm{PCD} / \mathrm{PhhB}$ is $\approx 80 \%$ pure, and it is further purified over a Q-Sepharose column (see Materials and Methods for conditions); the procedure leads to $\approx 40 \mathrm{mg}$ apparently homogeneous (SDS-PAGE, not shown) and functional PCD per liter $E$. coli culture. It is likely that the active center histidines are not involved in binding to the affinity column since all active center histidine mutants, including the double mutant $\mathrm{H} 73 \mathrm{~A}, \mathrm{H} 74 \mathrm{~A}-$ $\mathrm{PCD} / \mathrm{PhhB}$, in which only His91 is present, bind to the column with an affinity similar to that of wt-PCD. We thus infer that this binding is due to His8 and His 18 of the $\mathrm{N}$ terminal region.

\section{Characterization of Wild-Type PCD/PhhB}

Activity was measured using the so-called 'direct assay' in which the dehydration of 7,8-dihydropterin-4a-carbinolamine (CA; note that this molecule is the hydrated form of a 7,8-dihydropterin, which refers to the actual oxidation state of the molecule. Formally it is at the oxidation level of a tetrahydropterin. For simplicity, and since the term '7,8dihydro' has gained acceptance, the latter will be used) to the quinonoid 7,8-dihydro form is monitored directly by following the absorbance changes at $245 \mathrm{~nm}$ (Köster et al., 1995). The activity follows saturation kinetics using $\mathrm{BH}_{4}$ and the artificial substrate 6(S)-Me-CA (Figure 2). Thus $V_{\text {max }}$ for $\mathrm{PCD} / \mathrm{PhhB}$ is $\approx 3.5 \mathrm{nmol} / \mathrm{s}$, which, in turn, corresponds to $\approx 40 \%$ of that found for human wt-PCD (Figure 2). The $K_{\mathrm{m}}$ for $6(\mathrm{~S})-\mathrm{Me}-\mathrm{CA}$ is $20 \mu \mathrm{M}$ and thus essentially the same as that found for human PCD (25 $\mu \mathrm{M}$; Table 1), (Köster et al., 1996). On the other hand, using the 'coupled assay', which is based on the reactions shown in Scheme 1 (Citron et al., 1992), PCD/PhhB has nearly the same activity as human PCD (90\%; Table 1). Binding of the product analog quinonoid 6,6-dimethyl-7,8-dihydropterin (q-6,6- $-\mathrm{Me}_{2} \mathrm{PH}_{2}$ ), causes a nearly complete quenching of the tryptophan fluorescence at saturation and goes along with a $K_{\mathrm{d}}$ of $\approx 2 \mu \mathrm{M}$. This, again, is similar to the value found for human PCD $\left(K_{d} \approx 0.9 \mu \mathrm{M}\right.$; Köster et al., 1995). With 6(S)-Me-CA as substrate and using the direct assay an apparent $\mathrm{pK} \approx 8.4$ was estimated from the $\mathrm{pH}$ dependence of the activity (Figure 3 ). With human PCD a pK of $\approx 8.2$ was found for the same dependence.

\section{Properties of Mutant Proteins}

A striking feature emerging from the comparison of the sequences of PCD/PhhB and human PCD (Figure 1) is that essentially all residues assumed to take part in substrate binding or catalysis (Cronk et al., 1996; Köster et al., 1996) are conserved. The most prominent of these residues are the histidines 73, 74 and 91 (numbering according to PCD/PhhB) (Figure 4) (Köster et al., 1996). Histidines 73 and 74 form conserved hydrogen bonds to the residues

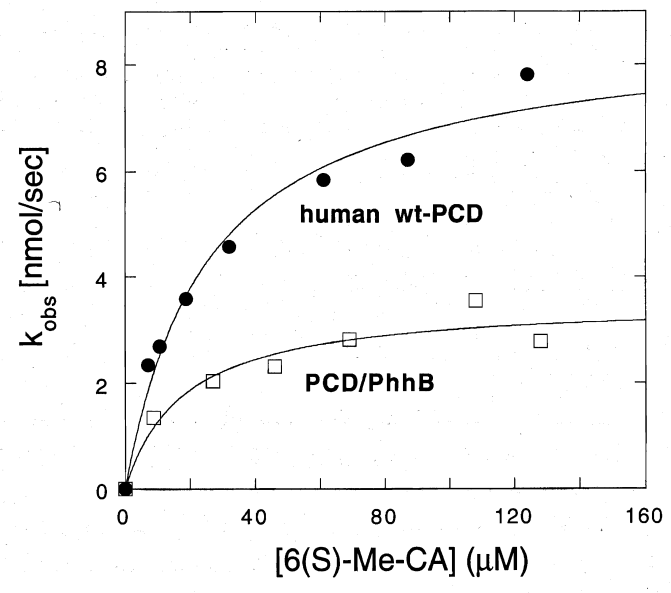

Fig. 2 Dependence of the Dehydration Rate of 6(S)-Me-CA Catalyzed by Human wt-PCD (๑) and wt-PCD/PhhB ( $\square)$.

Conditions: $[P C D]=0.3 \mu \mathrm{m}$ in $10 \mathrm{~mm}$ Tris $/ \mathrm{HCl} \mathrm{pH} 8.5$ at $10^{\circ} \mathrm{C}$. The observed rates were determined as initial rates in the direct assay (see Materials and Methods) and are corrected for the spontaneous decay of 6(S)-Me-CA (Köster et al., 1996). The lines are the best fits obtained using the Michaelis-Menten equation. The activity of $\mathrm{PCD} / \mathrm{PhhB}$ is $\approx 40 \%$ of the activity observed for human $\mathrm{PCD}$. The $K_{\mathrm{m}}$ value for PCD/PhhB is $20 \mu \mathrm{m}$ and is identical to that for human PCD (Köster et al., 1996).

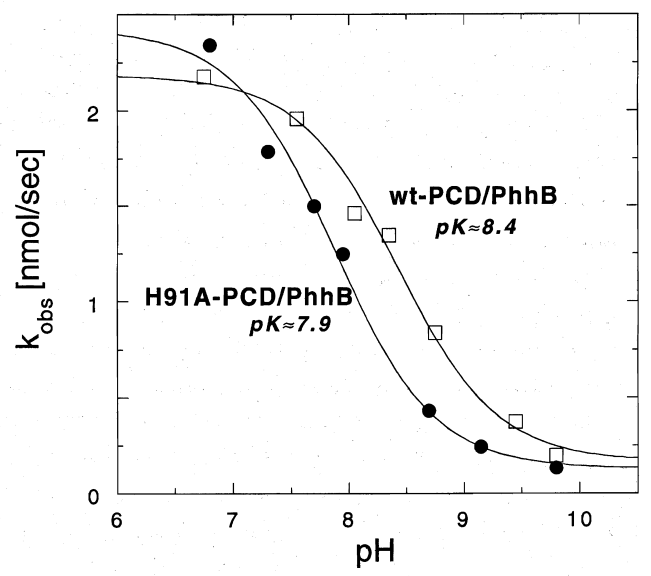

Fig. 3 pH Dependence of the Observed Dehydration Rates of 6(S)-Me-CA Catalyzed by wt-PCD/PhhB ( $\square$ ) and by the H91A$\mathrm{PCD} / \mathrm{PhhB}(\boldsymbol{\bullet})$.

The direct assays were performed at $10^{\circ} \mathrm{C}$ in $10 \mathrm{~mm}$ Tris $/ \mathrm{HCl}$ containing $0.1 \mathrm{M} \mathrm{KCl}$. [6(S)-Me-CA] $=25 \mu \mathrm{M}$, [wt-PCD/PhhB] = $0.3 \mu \mathrm{m}$ and $[\mathrm{H} 91 \mathrm{~A}-\mathrm{PCD} / \mathrm{PhhB}]=1 \mu \mathrm{m}$. The dehydration rates are corrected for the spontaneous decay of 6(S)-Me-CA at the corresponding $\mathrm{pH}$. The curves are the best fits obtained using an equation for one ionization.

Glu69 and Asp100 (Figure 4). These interactions might constitute 'classic' pairs involved in the catalytic activity (Köster et al., 1996). In order to assess their role in PCD/ $\mathrm{PhhB}$, histidines 73 and 74 have been separately and double mutated to alanine. Similarly Trp81, which is probably involved in substrate binding, has been mutated to alanine. The mutant proteins were expressed and purified to apparent homogeneity according to the scheme used for wt-PCD/PhhB; their catalytic properties are summarized in Table 1. 

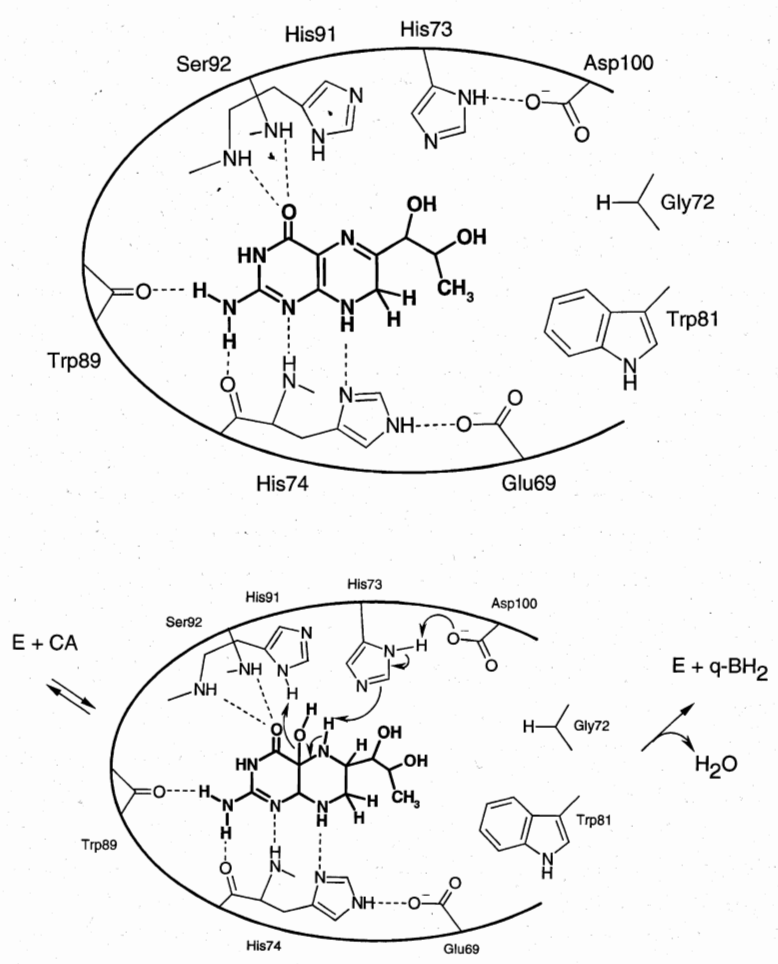

Fig. 4 Proposed Active Center Residues of PCD/PhhB.

The dashed lines indicate $\mathrm{H}$-bond interactions of ligands with active center residues. This arrangement corresponds to that found by Cronk et al. (1996) for the human enzyme in the complex with 7,8-dihydrobiopterin, which is shown in the upper part of the Figure. All amino acid residues that have been mutated and that are most probably involved in substrate binding and dehydration catalysis are shown. His 73 and His74 form conserved hydrogen bonds to Asp100 and Glu69, respectively. His91 is completely solvent exposed and appears to have unrestricted mobility. Trp81 lies directly in front of the entrance to the binding pocket. The lower part of the drawing depicts the proposed mechanism of dehydration. Note that this is similar to some of the mechanistic variants proposed by our groups (Köster et al., 1996) and by Cronk et al. (1966).

Both His73 and His74 single mutants, $\mathrm{H} 73 \mathrm{~A}$ and $\mathrm{H} 74 \mathrm{~A}$, and the 'double mutant' $\mathrm{H} 73 \mathrm{~A}, \mathrm{H} 74 \mathrm{~A}$ are completely inactive. The H91A-PCD/PhhB enzyme has $\approx 40 \%$ activity and its $K_{\mathrm{m}}$ for $6(\mathrm{~S})$-Me-CA is increased $\approx 3$-fold compared to wt-PCD/PhhB. The $\mathrm{pH}$ dependence of the activity of this mutant exhibits an apparent $\mathrm{pK}$ of $\approx 7.9$ compared to $\approx 8.4$ for wt-PCD/PhhB (Figure 3). The E69A mutant was expected to abolish the formation of the $\mathrm{H}$-bond to $\mathrm{His} 74$ (Figure 4), and thus to have similar drastic effects as observed with the corresponding human mutant. Somewhat unexpectedly the activity of E69A was $\approx 40 \%$ of that of wt-PCD/PhhB, while the $K_{\mathrm{m}}$ for substrate, and the $K_{\mathrm{d}}$ for binding of the product $\mathrm{q}-6,6-\mathrm{Me}_{2} \mathrm{PH}_{2}$ were essentially unaltered (Table 1). Similarly, the apparent pK observed for the $\mathrm{pH}$ dependent dehydration of substrate was unaffected compared to wt-PCD/PhhB. In human PCD mutation of Asp88, which is involved in hydrogen bonding with His61, results in an insoluble enzyme. The corresponding D100N-mutant of PCD/PhhB is soluble and the activity is less than $10 \%$ of that of the reference when measured in the direct assay. In the coupled assay using human wt$\mathrm{PAH}$ this mutant is inactive.

In addition to the above described mutants, which concern residues strictly conserved between human and bacterial $P C D$, two further residues belonging to the active center of PCD/PhhB were mutated. Trp81 corresponds to Tyr69 of human PCD and appears to cover the 'entrance' of the binding pocket. Indeed its mutation to alanine leads to an inactive enzyme while binding of the quinonoid product analog is extremely weak (Table 1). This contrasts to what was found with the analogous Y69A-mutant of human PCD, where only negligible effects on the enzymatic activity and on the binding of the product were observed (Table 1) (Köster et al., 1996). The second examined residue which is Asp60 of human PCD, which corresponds to Gly72 in PCD/PhhB. Asp60-COO- interacts with the side chain $1^{\prime} \mathrm{OH}$ of the product analog 7,8-dihydrobiopterin (Cronk et al., 1996). The G72D mutant of $\mathrm{PCD} / \mathrm{PhhB}$ has $\approx 75 \%$ of the activity of the wt-protein using 6(S)-Me-CA in the direct assay, and $\approx 65 \%$ in the coupled assay. Surprisingly, using $6(\mathrm{~S})$-propyl-CA as substrate in the direct assay the activity of the mutant is restored to $\approx 100 \%$ (not shown).

\section{Discussion}

\section{Interactions with Substrate/Product}

The three-dimensional structure of homodimeric PCD/ $\mathrm{PhhB}$ is closely similar to that of a dimer subunit of the homotetrameric human PCD (Ficner, R., Sauer, U.H., Stier, G., Ceska, T.A., and Suck, D., personal communication; Köster et al., 1997). Most of the residues that are assumed to take part in substrate binding and/or catalysis in human PCD are conserved in the bacterial enzyme. This suggests the same basic mode of binding, and this is supported by the following findings: first, with the direct assay and using the synthetic substrate $6(\mathrm{~S})$-Me-CA comparable $K_{\mathrm{m}}$ values are found for wt-PCD/PhhB and for human wt-PCD (Table 1) (Köster etal., 1996). Second, the affinity of the two PCD's for the product analog $\mathrm{q}-6,6-\mathrm{Me}_{2} \mathrm{PH}_{2}$ as reflected by their $K_{d}$ 's are very similar. Third, in the G72D-PCD/ PhhB-mutant, in which Gly72 is mutated to the corresponding residue of human PCD (Asp60), binding of the quinonoid product is tighter than with wt-PCD/PhhB and essentially the same as with mammalian PCD (Table 1), as indicated by comparable $K_{\mathrm{m}}$ values. Fourth, Trp81 in PCD/ PhhB corresponds to Tyr69 in human PCD, a residue which is contributed to the active center of one monomer of PCD from the neighboring subunit (Cronk et al., 1996, Köster et al., 1996). Trp81 is directed towards the side chain of bound substrate and might therefore interact with it. It should be noted that Tyr69 of human PCD does not appear to interact with the side chain (Cronk et al., 1996). It is thus somewhat surprising that the W81A-PCD/PhhBmutant exhibits weak product binding and is essentially inactive (Table 1). This might result from the substantially larger Trp side chain compared to that of Tyr. 
The comparison of the binding of the substrate pyrimidine (2)- $\mathrm{NH}_{2}-\mathrm{N}(3)-\mathrm{C}(4)=\mathrm{O}$ moiety, which is assumed to represent the 'recognition site' of the substrate, of $\mathrm{PCD} /$ PhhB with that of human PCD is of interest. From this comparison the conclusion appears justified that the basic mode of recognition is very similar in the bacterial and human enzyme, although different amino acids are involved. Thus the following pairs/replacements are found for human and PCD/PhhB, respectively: His62-His74, Ser77-Trp89, His79-His91 and Glu80-Ser92 (Figure 1).

\section{Dehydration Mechanism}

The conclusion emerging from the activity study of the PCD/PhhB-mutants is the identity of the assumed key functional groups between the bacterial and the human proteins. The effects observed upon substitution particularly of the active center histidines are essentially identical (Table 1). From this we conclude that the same basic mechanism of dehydration, as proposed earlier (Köster et al., 1996), is operative in both proteins. However, some differences are also evident. A noticeable one is the $\approx 40 \%$ activity of the E69A mutant, which contrasts with an inactive human E57A mutant (Table 1). From an inspection of the 3D-structure (Ficner, R., Sauer, U.H., Stier, G., Ceska, T.A., and Suck, D., personal communication, Köster et al., 1997) there is no group equivalent to the Glu69-COO- in the vicinity which could take over the role of the latter in forming a $\mathrm{H}$-bond with $\mathrm{His} 74$, the base assumed to interact with the $\mathrm{N}(8)-\mathrm{H}$ of the pterin (Figure 4). It is thus probable that formation of a base pair is not vital in this case, and that charge can be relayed directly from $\mathrm{His} 74$, e.g. to the solvent. In agreement with this, the H74A (bacterial) and the H62A (human) mutants have low activities. It should be noted that the lower activity of the H91A mutant (compared to wt-PCD/PhhB) reported in Table 1 is not an intrinsic one, but results from a shift of the $\mathrm{pH} /$ activity profile, i.e. of the apparent $\mathrm{pK}$ induced by the mutation. Thus, at $\mathrm{pH}<$, and $>$ pK the activity of mutant and wt-PCD/PhhB are essentially identical (Figure 3). This clearly indicates that His91, which does not appear to be in specific contact with further residues (Ficner, R., Sauer, U.H., Stier, G., Ceska, T.A., and Suck, D., personal communication, Köster et al., 1997), is not essential for activity. The observed pH shift might be simply, due to the increase in hydrophobic character induced by the mutation. The minor difference in the observed pK's between the bacterial and mammalian enzyme might reflect similar differences in the polarity of the active centers (Table 1).

\section{Functional Role of PCD/PhhB}

With respect to the 'enzymatic properties' of PCD/PhhB, the present results confirm the assumption that the bacterial protein has the same function as the mammalian one, i.e. it is involved in the hydroxylation of aromatic amino acids, and probably of phenylalanine. This implies that the rate of spontaneous dehydration of pterin-4a-carbinolamines is too low for sustaining the hydroxylation cycle also in bacterial cells (cf. Scheme 1). A role in prevention of the formation of 7-substituted pterins, which is considered important in humans (Curtius et al., 1990), is also conceivable: accumulation of the latter might be harmful also to the bacterial cell if elimination mechanisms are not efficient. This suggests that PCD/PhhB is a bifunctional protein also in bacteria, where its regulatory role has been suggested only in the specific Pseudomonas strain (Zhao et al., 1994). Also in such cases the intriguing possibility exists that pterins or related small molecules interact with $\mathrm{PCD} / \mathrm{PhhB}$ and in this process modulate the regulatory function of the enzyme. This possibility will be explored in forthcoming studies. Finally, and from a phylogenetic point of view, the maintenance of both activities of PCD in bacteria and mammals suggests that both are ancient and vital features.

\section{Materials and Methods}

\section{Enzymes and Chemicals}

L-phenylalanine, phenylmethylsulfonyl fluoride, $p$-amino-benzamidine-agarose, and dihydropteridine reductase were obtained from Sigma, catalase and NADH from Boehringer Mannheim, $\mathrm{BH}_{4}$ from Schircks Laboratory (Jona, Switzerland), $\mathrm{Ni}^{2+}$-nitriloacetic acid-agarose from Qiagen, thrombin from Novagen. Recombinant human $\mathrm{PAH}$ in form of a fusion protein with maltose binding protein was a gift from Prof. Flatmark, Bergen, Norway. 6(S)methyl- and 6(S)-propyl-CA were prepared according to Bailey et al.(1992) with slight modifications (Köster et al., 1995).

\section{Instrumentation}

UV-visible spectra were recorded either with a Uvikon-810 or -930 spectrophotometer (Kontron); fluorescence emission and excitation spectra with a fluorimeter Model SFM-25 from Kontron. Reaction rates were obtained from fits of primary kinetic traces using program A (Dr. D. Ballou, University of Michigan, Ann Arbor, USA). Kinetic constants were calculated using the program KaleidaGraph and appropriate algorithms.

\section{Assays}

For the assessment of dehydratase activity in the so-called 'enzyme coupled assay' a modification of the assay procedure described by Citron et al. (1992) was used. Conditions: $0.1 \mathrm{M}$ Tris$\mathrm{HCl} \mathrm{pH} 8.4$ at $25^{\circ} \mathrm{C}$, containing $20 \mu \mathrm{g}$ catalase, 0.5 units of dihydropteridine reductase, $0.2 \mathrm{nmol}$ recombinant human $\mathrm{PAH}$, $1 \mu \mathrm{mol}$ L-phenylalanine, $2.9 \mathrm{nmol} \mathrm{BH}$, and $100 \mathrm{nmol} \mathrm{NADH}$ in $1.0 \mathrm{ml}$. The consumption of NADH was followed at $340 \mathrm{~nm}$ according to Kaufman (1979). The activity of PCD is expressed as the rate acceleration of $\mathrm{NADH}$ consumption $(\triangle 340 \mathrm{~nm})$ compared to the same rate measured in the absence of PCD (Köster et al., 1996). The 'direct assay', which is based on the use of CA as substrate, and determination of the $\mathrm{pH}$-dependence of activities were carried out as described (Köster et al., 1996). The estimation of binding constants also followed the procedures described earlier (Köster et al., 1995, 1996).

\section{Construction of Expression Vectors}

Mutants were produced by standard PCR techniques and cloned in a pET9d (Studier et al., 1990) derived plasmid between an Ncol and a Kpnl site at the 3 'end of the polylinker. 


\section{Protein Purification}

$\mathrm{PCD} / \mathrm{PhhB}$ and the mutant enzymes were purified by affinity chromatography over a $\mathrm{Ni}^{2+}$-nitriloacetic acid-agarose column in a similar manner as detailed previously (Köster et al., 1996). However, it should be noted that the enzyme contains no 'His-tag' that is usually required for the complexation of the $\mathrm{Ni}^{2+}$-agarose. $\mathrm{PCD} / \mathrm{PhhB}$ nevertheless binds to the column due to the presence of five structurally closely located histidines. The purification conditions, however, had to be altered compared to previous conditions (Köster et al., 1996). Proteins were expressed in BL21(DE3) by inducing the cells at OD $1(600 \mathrm{~nm})$ with $0.2 \mathrm{~mm}$ isopropyl $\beta$-Dthiogalactopyranoside. After $2 \mathrm{~h}$ at $37^{\circ} \mathrm{C}$ bacteria were harvested and frozen in liquid nitrogen. Cells were lysed with buffer $\mathrm{A}$ containing $20 \mathrm{~mm}$ Tris- $\mathrm{HCl} \mathrm{pH8.0,200} \mathrm{mM} \mathrm{NaCl,} 1 \mathrm{~mm}$ phenylmethylsulfonyl fluoride plus $0.2 \%$ Igepal and $200 \mu \mathrm{g} / \mathrm{g}$ cells lysozyme. Viscosity was reduced by brief sonication and debris removed by centrifugation at $40000 \mathrm{~g}$ for $1 \mathrm{~h}$. The supernatant was mixed with $\mathrm{Ni}^{2+}$-nitriloacetic acid-agarose resin and incubated on ice for 30 $\mathrm{min}$. The $\mathrm{Ni}^{2+}$-agarose was then packed into a poly-prep column (Biorad) and the flow-through applied once more onto the column to assure complete binding of the $\mathrm{PCD}$ protein. The $\mathrm{Ni}^{2+}$-agarose was first washed with buffer $A$, then with buffer $A$ containing $1 \mathrm{M}$ $\mathrm{NaCl}$. The protein was eluted with 5 column volumes of $20 \mathrm{~mm}$ Tris- $\mathrm{HCl} \mathrm{pH} \mathrm{8.0,} 10 \mathrm{~mm}$ imidazole and $150 \mathrm{~mm} \mathrm{NaCl}$. The eluate was loaded directly onto a Q-Sepharose column that had been equilibrated with $25 \mathrm{~mm}$ Tris-HCl, $\mathrm{pH}$ 8.3. The Q-Sepharose column was washed with 5 column volumes of equilibration buffer and the protein eluted with 2 column volumes of $25 \mathrm{mM}$ Tris- $\mathrm{HCl}$ $\mathrm{pH} 8.3$ containing $250 \mathrm{~mm} \mathrm{NaCl}$. This procedure leads to some minor losses of protein, but delivers apparently pure material.

\section{Acknowledgement}

We thank Dr. Ralf Ficner, University of Marburg, Germany, for providing the manuscript on the structure of bacterial PCD prior to publication and Dr. T. Flatmark, Univ. of Bergen, Norway, for the generous gift of human recombinant phenylalanine hydroxylase. This work was supported by grants from the Deutsche Forschungsgemeinschaft to $S$. G. (Gh 2/7-1).

\section{References}

Ayling, J.E., Rebrin, I., Bailey, S.W., and Thöny, B. (1997). Mechanism of dehydration by the bifunctional protein, 4a-hydroxytetrahydropterin dehydratase/DCoH. In: Chemistry and Biology of Pteridines and Folates, W. Pfleiderer, and $\mathrm{H}$. Rokos, eds. (Berlin - Vienna: Blackwell Wiss.-Verlag), pp. 565-570.

Bailey, S.W., Chandrasekaran, R.Y., and Ayling, J.E. (1992). Synthesis of tetrahydropteridine C6-stereoisomers, including $\mathrm{N}^{5}$ formyl-(6S)-tetrahydrofolic acid. J. Org. Chem. 57, 44704477.

Citron, B.A., Davis, M.D., Milstien, S., Gutierrez, J., Mendel, D.B., Crabtree, G.R., and Kaufman, S. (1992). Identity of 4a-carbino- lamine dehydratase, a component of the phenylalanine hydroxylation system, and $\mathrm{DCoH}$, a transregulator of homeodomain proteins. Proc. Natl. Acad. Sci. 89, 11891-11894.

Cronk, J. D., Endrizzi, J. A., and Alber, T. (1996). High-resolution structures of the bifunctional enzyme and transcriptional coactivator $\mathrm{DCoH}$ and its complex with a product analogue. Protein Science 5, 1963-1972.

Curtius, H.-Ch., Adler, C., Rebrin, I., Heizmann, C.W., and Ghisla, S. (1990). 7-substituted pterins: Formation during phenylalanine hydroxylation in the absence of dehydratase. Biochem. Biophys. Res. Commun. 172, 1060-1066.

Endrizzi, J.A., Cronk, J.D., Wang, W., Crabtree, G.R., and Alber, T. (1995). Crystal Structure of DCoH, a bifunctional, protein-binding transcriptional coactivator. Science 268 (5210), 556-559.

Ficner, R., Sauer, U.H., Stier, G., and Suck, D. (1995). Three-dimensional structure of the bifunctional protein PCD/DCoH, a cytoplasmic enzyme interacting with transcription factor HNF1. EMBO J. 14, 2034-2042.

Kaufman, S. (1970). A protein that stimulates rat liver phenylalanine hydroxylase. J. Biol. Chem. 245, 4751-4759.

Kaufman, S. (1976). On the nature of an intermediate that is formed during the enzymatic conversion of phenylalanine to tyrosine, Adv. Exp. Med. Biol. 74, 91-102.

Kaufman, S. (1979). The activity of 2,4,5-triamino-6-hydroxypyrimidine in the phenylalanine hydroxylase system. J. Biol. Chem. 254, 5150-5154.

Köster, S., Thöny, B., Macheroux, P., Curtius, H.-Ch., Heizmann, C.W., Pfleiderer, W., and Ghisla, S. (1995). Human pterin-4acarbinolamine dehydratase/dimerization cofactor of hepatocyte nuclear factor-1a. Eur. J. Biochem. 231, 414-423.

Köster, S., Stier, G., Ficner, R., Hölzer, M., Curtius, H.-Ch., Suck, D., and Ghisla, S. (1996). Location of the active site and proposed catalytic mechanism of pterin-4a-carbinolamine dehydratase. Eur. J. Biochem. 241, 858-864.

Köster, S., Curtius, H.-C., Ghisla, S., Ficner, R., Stier, G., Suck, D., and Sauer, U. H. (1997). In: Chemistry and Biology of Pteridines and Folates. W. Pfleiderer, and H. Rokos, ed. (Berlin - Vienna: Blackwell Science), pp. 571-576

Mendel, D.B., Khavari, P.A., Conley, P.B., Graves, M.K., Hansen, L.P., Admon, A., and Crabtree, G.R. (1991). Characterization of a cofactor that regulates dimerization of a mammalian homeodomain protein. Science 254, 1762-1767.

Nikolov, D.B., Hu, S.H., Lin, J., Gasch, A., Hoffmann, A., Horikoshi, M., Chua, N.H., Roeder, R.G., and Burley, S.K. (1992). Crystal structure of TFIID TATA-box binding protein. Nature 360 (6399), 40-46.

Studier, F.W., Rosenberg, A. H., Dunn, J. J., and Dubbendorf, J. W. (1990). Use of T7 RNA polymerase to direct expression of cloned genes. Meth. Enzymol. 185, 60-85.

Zhao, G., Xia, T., Song, J., and Jensen, R.A. (1994).Pseudomonas aeruginosa possesses homologues of mammalian phenylalanine hydroxylase and $4 \alpha$-carbinolamine dehydratase/DCoH as part of a three-component gene cluster. Proc. Natl. Acad. Sci. 91, 1366-1370. 